\title{
AUTOMATIC ROOM LIGHT CONTROLLER USING MICROCONTROLLER AND VISITOR COUNTER
}

\author{
Kimbley $^{1}$, Rachit Mehrotra ${ }^{2}$, Sohail Ahmed Khan ${ }^{3}$, Sonali K. Pawar ${ }^{4}$

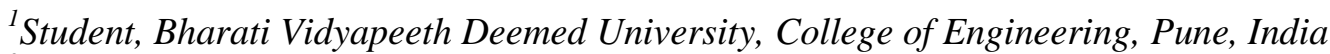 \\ ${ }^{2}$ Student, Bharati Vidyapeeth Deemed University, College of Engineering, Pune, India \\ ${ }^{3}$ Student, Bharati Vidyapeeth Deemed University, College of Engineering, Pune, India \\ ${ }^{4}$ Assistant Professor, Electronics Bharati Vidyapeeth Deemed University, College of Engineering, Pune, India
}

\begin{abstract}
The Project 'Automatic Room Light Controller Using microcontroller ATMEGA16A and bidirectional visitor counter' controls a room light as well as count the number of individuals entering and leaving a room. When an individual enters into a room then one counter is incremented by one and one light in a room will be switched ON and when the individuals leaves a room then the counter is decremented by one. When the number of individuals in a room is greater than 5 then 2 lights will be switched ON. When the individuals in a room are more than 10 then 3 lights will be switched ON. Similarly on increase of every 5 individuals one more light will switched ON. Lights will turn OFF when all the individuals go out of a room. The total number of individuals present inside a room is also displayed on the LCD display. IR sensors and microcontroller does above job. IR sensors sense the obstruction and microcontroller receives the signals produced by the obstruction from the sensors. The received signal is operated via program stored in ROM of Microcontroller..
\end{abstract}

Keywords: Microcontroller ATMEGA16A, IR Sensors, LCD, Counters

\section{INTRODUCTION}

In this digital word we need every possible thing around us to be automatic which reduces human efforts. There are increasing electronic circuits that make today's life easier and simple. Nowadays Energy Crisis is the big problem faced by everyone. So there is a need to conserve energy. This project is very useful for such problems as one generally forgets to turn off lights and fans while leaving a room. The aim of this is to make an automatic controller based prototype to count the number of individuals entering in the particular room and accordingly light up a room. This project has two parts. One is "Individual count" and other is "Automatic room light Controller" We use IR sensors to detect number of individuals entering in a room. This circuit counts the number of individuals and displays the count on the seven segment LCD display to avoid congestion. This project is very helpful in schools and colleges for their auditorium. "AUTOMATIC ROOM LIGHT CONTROLLER USING MICROCONTROLLER AND VISITOR COUNTER" as the name specifies that it controls the task of counting the number of individuals and lights of a room with accuracy. When an individual enters into a room then one counter is incremented by one and one light in a room will be switched $\mathrm{ON}$ and when the individuals leaves a room then the counter is decremented by one. When there is no individual in a room then lights will be switched off automatically.

\subsection{Hardware Requirements}

- $\quad$ Microcontroller ATMEGA16A: 8-bit $\mu \mathrm{C}$ having $16 \mathrm{~K}$ Bytes In-System Programmable Flash
- IR sensors

- Seven Segment LCD Display: 5V dc

- $\quad$ Step down Transformer: $12 \mathrm{~V}, 50 \mathrm{~Hz}, 1 \mathrm{AMP}$

- Relay Unit: $+12 \mathrm{~V}$ dc to $230 \mathrm{~V}$ ac

- Power Supply: 230V,5Hz ac

- Bridge Rectifier: 20V,2Amp

- Electrolytic Capacitor: (1000 $\mu \mathrm{f}, 35 \mathrm{~V})$ and $(10 \mu \mathrm{f}, 63 \mathrm{~V})$

- Ceramic capacitor: $220 \mu \mathrm{f}$

- LED: $2 \mathrm{~V}$ or $3 \mathrm{~V}$

- Registers

- Transistor: BC108

- Diodes: IN4004

- $\quad$ PCB (Printed circuit board)

\subsection{Software Requirements}

- $\quad$ Embedded C.

- Proteus(Processor for text East to use): It is a Software used for simulation and designing PCB layout. It was created by Simone Zanella in 1998. It is fully functional and procedural. It consists of many functions and languages.

- Flash Magic

It is used for burning program into microcontroller.

\section{OVERVIEW OF DESIGN}

The basic block diagram of the automatic light controller using microcontroller and bidirectional visiting counter is shown in the figure below. It consists of six blocks. 


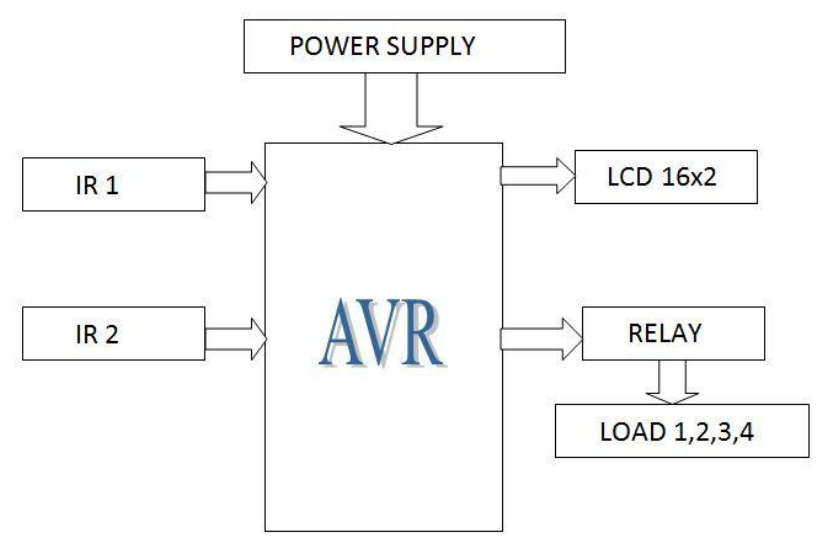

Fig -3: Schematic Diagram

\section{Power Supply}

We have used $+12 \mathrm{~V}$ and $+5 \mathrm{~V}$ dc power supply. Step down transformer off 1 Amp, $230 \mathrm{~V}, 50 \mathrm{~Hz}$ provides $+12 \mathrm{~V}$ ac supply. It provides required amount of voltage to components. $+12 \mathrm{~V}$ is given to relay driver circuit. $\mu \mathrm{C}$ and $\mathrm{LCD}$ require $5 \mathrm{~V}$ dc supply so to fulfill the requirement we have used regulated IC 7805 .

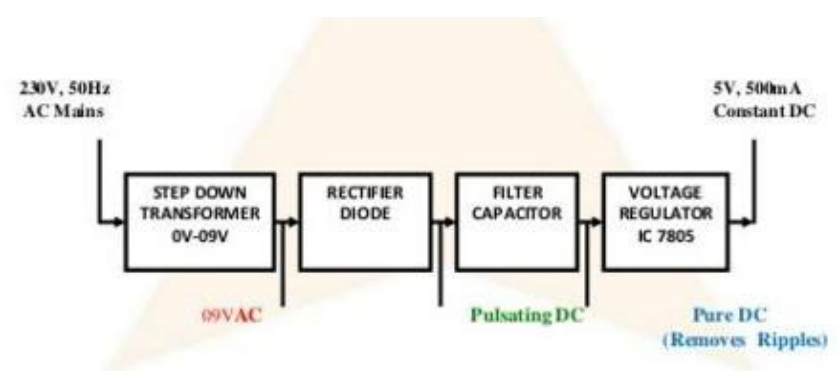

Fig -1: Power Supply

\section{IR Sensors}

IR sensors are used to produce IR waves. In this Project there are two IR sensors. IR sensors consist of IR Transmitter and IR receiver. IR1 detects the numbers of individuals entering a room. IR2 detects the number of individuals leaving a room. The frequency range of IR sensors varies depending upon its cost. By using LED light at specified wavelength as required by the sensor, we can look at the intensity of the received light. When any object cuts the light emitted by LED, the light bounces back from the object to the light sensor. This results in a large change in the intensity, which is detected by receiver of IR sensor .

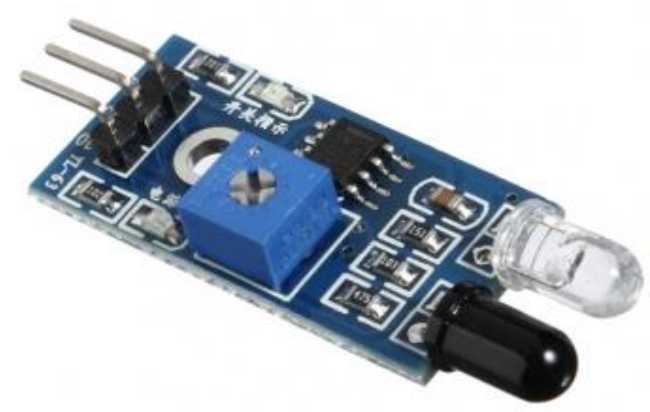

Fig -3: Schematic Diagram

\section{Microcontroller ATMEGA16A}

Microcontroller is a single chip that contains the processor (CPU),ROM, EPROM, EEPROM, RAM , clock and I/O ports. ATMEGA16A is a 8-bit Microcontroller with $16 \mathrm{~K}$ Bytes In -System Programmable Flash . Its Power Consumption @ $1 \mathrm{MHz}, 3 \mathrm{~V}$, and $25^{\circ} \mathrm{C}$-Active: $0.6 \mathrm{~mA}-$ Idle Mode: $0.2 \mathrm{~mA}-$ Power -down Mode: < $1 \mu \mathrm{A}$. The ATmega16A is a low-power 8-bit microcontroller based on the Atmel AVR enhanced RISC architecture. It executes instructions in a single cycle. ATmega16A achieves throughputs approaching 1MIPS per $\mathrm{MHz}$ allowing the system design to optimize power consumption versus processing system. XTAL1 gives Input to the inverting Oscillator amplifier and input to the internal clock operating circuit. XTAL2 pin is used for Output from the inverting Oscillator amplifier. Microcontroller is the heart of the circuit. It does the job of room light controller as well as counting number of individuals entering and leaving a room accurately. $\mu \mathrm{C}$ continuously monitors the IR receivers and executes the program stored in its ROM when it receives the signal from the sensors.

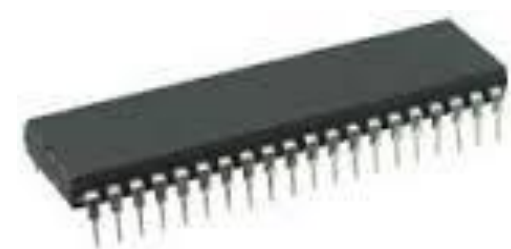

Fig -1: Microcontroller ATMEGA16A

\section{LCD 16x2}

LCD (Liquid Crystal Display) is used to display number of individuals in a room. It is very thin technology based on combination of liquid and crystal. Liquid state produces an image for display.

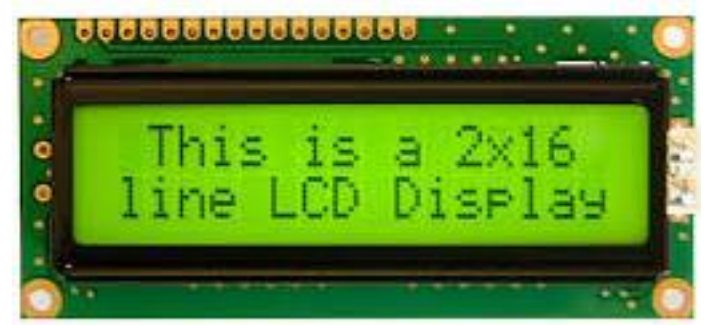

Fig -1: LCD Display

\section{Relay Driver Circuit}

In relay driver circuit there are transistors, diodes and the relays. Relay driver circuit is used to control the light. This block can drive the various controlled devices. We are using $+12 \mathrm{~V}$ dc relay. As $\mu \mathrm{C}$ cannot drive relay directly so output signal from microcontroller is passed to the base of the transistor, which activates the particular relay so that it can select particular device to operate. Relays can control the charge flowing to the load. Load may be and AC device such as light, fan, Bulb etc. 


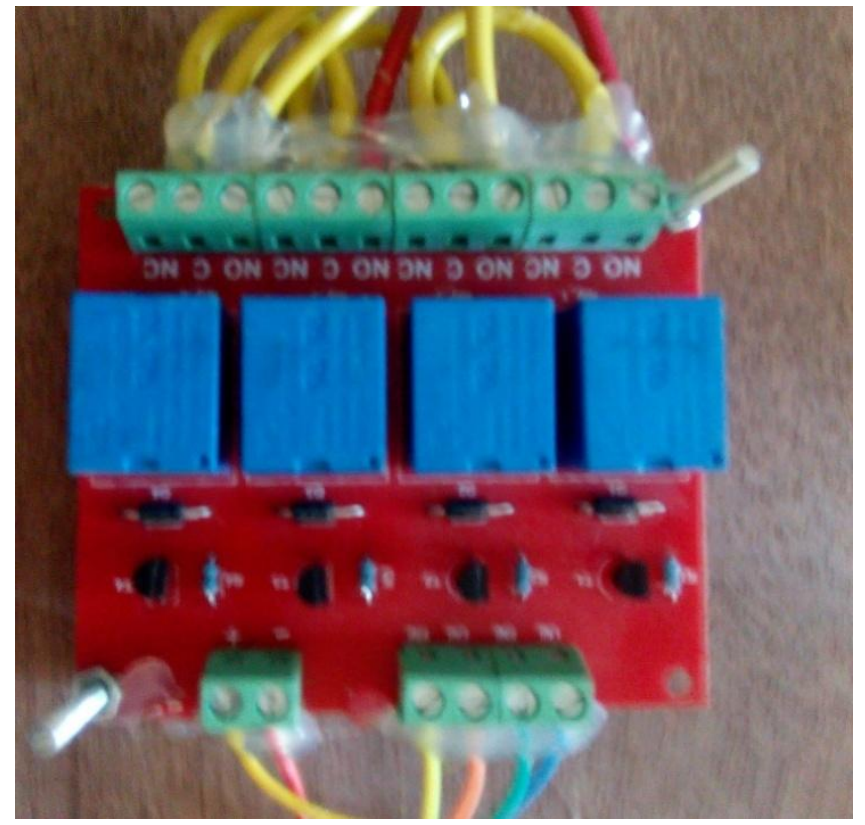

Fig -2: Relay Driver Circuit

\section{Load}

Relays control the flow of charge to the load. In this project we have used four bulbs of 10 Watt each as a load. But we can use any electronic object like tubelight, CFL, fans, cooler etc in place of bulbs.

\subsection{Working}

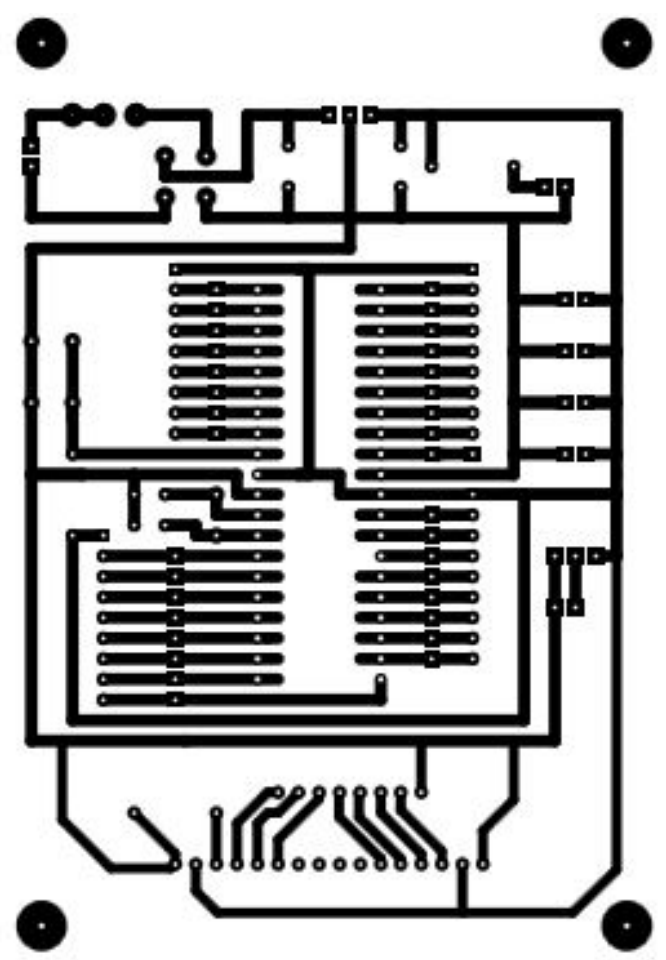

Fig -2: Circuit Layout

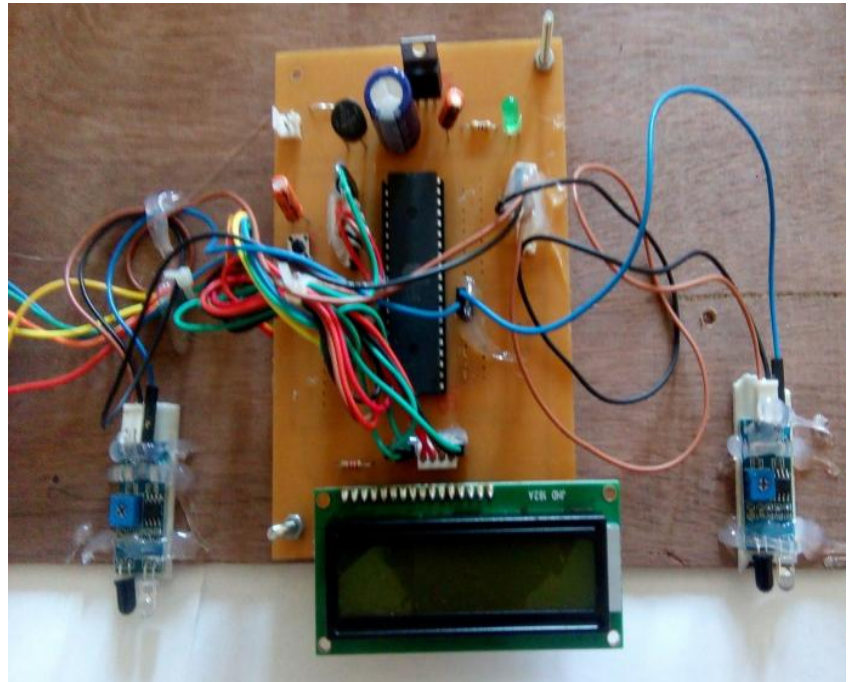

Fig -3: Circuit Board

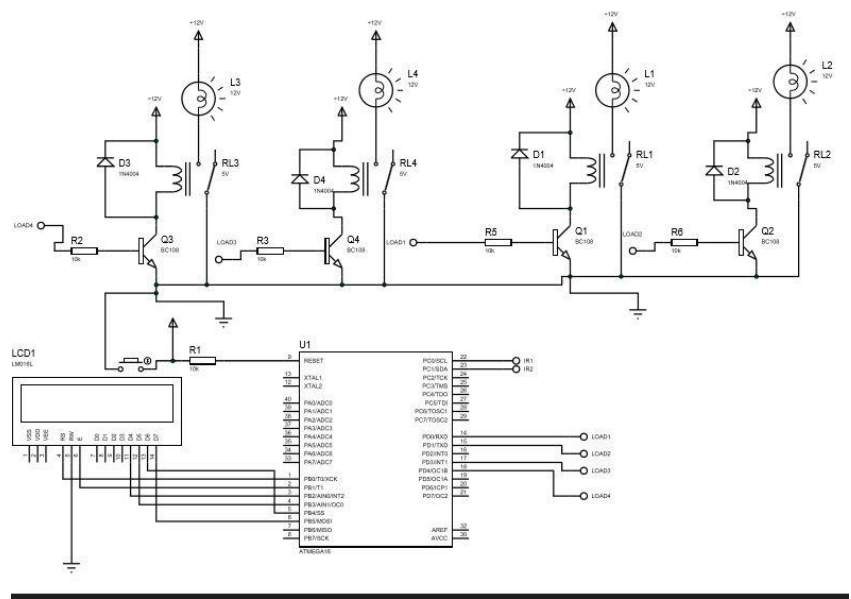

Fig -4: Circuit Diagram

In this setup IR sensors transmit $40 \mathrm{kHz}$ IR signal to receiver. The $\mu$ Controller continuously monitors the signal transmitted by IR sensors.IR1 is connected to PortC.6 and IR2 is connected to PortC. 7 of $\mu \mathrm{C}$. Initially we kept PC $6=1$ and $\mathrm{PC} 7=1$. When any object passes from entry sensor a signal is generated and output of IR sensor gives low trigger to $\mu \mathrm{C}$ pin PC6 then the counter on display will be incremented by one. When any object passes from exit sensor a signal is generated and output of IR sensor gives low trigger to $\mu \mathrm{C}$ pin PC7 then the counter on display will be decremented by one. When there is nobody in a room counter displays ' 00 ' then relays are OFF \& lights are OFF.

In this project, no. of lights in a room will glow according to the individuals entering in a room.

- If the count is 1 or $<6$ only one light will glow.

- If the count is 6 or $<11$ two lights will glow.

- If the count is 11 or $<16$ three lights will glow.

- If the count is 16 or $<256$ four lights will glow. 


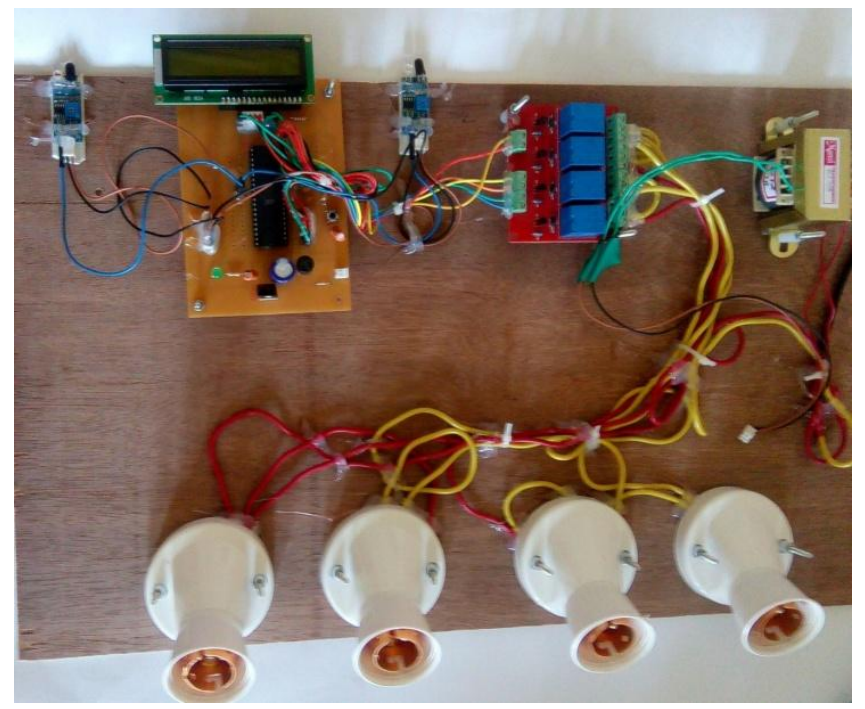

Fig -1: Circuit Board

\section{CONCLUSIONS}

In this digital world Technology is very advanced and we prefer things to be done automatically without any human efforts. This project also helps to reduce human efforts. Also it is very useful to conserve resources. It is very useful in Schools, hospitals, malls, offices, auditoriums etc.

In any big hall if we want to count number of individuals it is very difficult as it results in congestion and disturbance to the whole Class. This project becomes helping hand in such situation because it gives the count on LCD display. Also it controls the lighting system automatically according to how many individuals are there in a room.

- Turning ON of lights will increase with increasing the individuals in a room.

- Turning ON of lights will decrease with decreasing the individuals in a room.

\section{ACKNOWLEDGEMENT}

We have taken efforts to complete this project. But this would not be possible without the help of our team. We are very thankful to all of them.

Also we are thankful to Prof. SK PAWAR for her guidance, supervision and providing important data regarding the project named "AUTOMATIC ROOM LIGHT CONTROLLER USING MICRO CONTROLLER AND VISITOR COUNTER".

We would also like to thanks our parents for their support and encouragement which gives us inner strength to complete this work.

\section{REFERENCES}

[1]. ATmega16A Datasheet - Atmel http://www.atmel.com/images/atmel-8154-8-bit-avratmega16a_datasheet.pdf

[2].http://education.rec.ri.cmu.edu/content/electronics/boe/ir _sensor/1.html
[3] Automatic Room Light Controller with bidirectional visitor counter | VOL-I Issue-4| ISSN: 2395-4841 .http://www.ijictrd.net/papers/IJICTRDV1I4005.pdf

[4].http://www.digchip.com/datasheets/parts/datasheet/105/ CL100-pdf.php

[5].http://www.datasheetarchive.com/dlmain/Datasheets312/174867.pdf

[6].https://www.fairchildsemi.com/datasheets/LM/LM7805. pdf

[7] www.ijictrd.net

[8] www.slideshare.net

[9] lib.chipresistor.ru

[10]."Sir Syed University of Engineering and Technology (SSUET) students prepare automatic electric consum", Balochistan Times (Baluchistan Province,, Dec 242010 Issue

[11] tutorial.cytron.com.my

[12].ocr.org.uk

[13].Jalovaara, P.. "Air bacterial and particle counts in total hip replacement operations using non-woven and cotton gowns and drapes", Journal of Hospital Infection, 198911

[14].etheses.saurashtrauniversity.edu

\section{ORIGINALITY REPORT PRIMARY}

SOURCES www.ijictrd.net Internet [6].www.slideshare.net Internet lib.chipresistor.ru Internet "Sir Syed University of Engineering and Technology (SSUET) students prepare automatic electric consum", Balochistan Times (Baluchistan Province, Dec 242010 Issue Publications

[15].tutorial.cytron.com.my

[16].www.idrbt.ac.in

[17].www.education.rec.ri.cmu.edu

[18]. www.atmel.com

[19].www.acdconline.com

\section{BIOGRAPHIES}

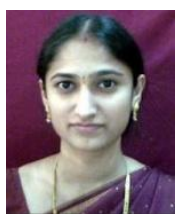

Sonali K. Pawar is an assistant professor in Electronics Department at Bharati Vidyapeeth Deemed University College of Engineering Pune. She guides us to make this project at every point.

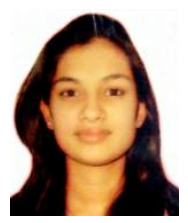

Kimbley is a student (B.TECH) in Electronics Engineering at Bharati Vidyapeeth Deemed University College of Engineering Pune. Her research focuses on microcontroller system design.

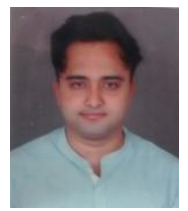

Sohail Ahmed Khan is a student (B.TECH) in Electronics Engineering at Bharati Vidyapeeth Deemed University College of Engineering Pune. His research includes electronic system design and components.

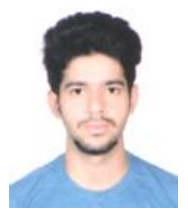

Rachit Mehrotra is a student (B.TECH) in Electronics Engineering at Bharati Vidyapeeth Deemed University College of Engineering Pune. His research focuses on Power devices. 